\title{
INFLUENCE OF SEASONAL FACTOR ON THE CHEMICAL COMPOSITION OF PERSIMMON
}

\author{
Irina Bejanidze ${ }^{1}$, Tina Kharebava ${ }^{2}$, Nargiz Alasania ${ }^{3}$, \\ Nato Didmanidze ${ }^{4}$, Nazi Davitadze ${ }^{5}$
}

\begin{abstract}
Persimmon is one of the most popular and favorite fruits not only in Georgia, but also in other countries. People love it for its unique specific taste and high nutritional value. There are more than 500 types of persimmon, properties and tastes which depend on the persimmon growing conditions.

The purpose of this project was to study the persimmon fruit chemical composition, the regularity in the quantity changes of the bioactive substances and technical-economical persimmon parameters during its storage and technological processing; to develop a highly profitable and efficient composite production technology for a new assortment of products and high quality beverages. Organoleptic and chemical tests of 12 persimmon fruit varieties were made. The content and composition of sugars, polyphenols, pectin, and tanning substances, were defined; and the relation of these parameters to the fruit maturity degree, the dynamics of their change in the ripening and storage process were determined. In addition, we determined the content of sugars ( inverted, total, saccharose), tanning substances (free, total), polyphenols and nitrogen through a spectrophotometric method, dry solids through a refractometric method, pectin (total, soluble, protopectin) and acidity through a potentiometric method, and cellulose through a chlorite method. The feasibility of the persimmon fruit industrial processing was established. Persimmon fruit of Khachia and Khiakume varieties were proved to be the best raw material for the industrial production of a fruit alcohol and beverages. It should be noted here that persimmon fruit must be harvested in November when they have a dark orange colouring and their dry solids content reaches $18 \%$, inverted sugars make up 16$16.5 \%$, and the acidity is $0.12 \%$. For concentrate production, persimmon must be harvested in October when the fruit are yellow and their tanning and colouring substances reach $1.24 \%$, and pectin substances make up $0.77 \%$. The fruit sugars are glucose and fructose, generally in equal quantities. Tanning substances, leicoantocianes, in particular, are responsible for the tart taste; the lower their content is, the less the tart taste is felt, moreover, ripe fruit are less tart in flavour which is due to the tanning substances getting bound with high molecular substances. All the 12 persimmon varieties cultivated in Georgia can be used as raw material, including substandard and overripe fruit that are not marketable and do not have a long shelf life.
\end{abstract}

UDC Classification: 547.1, DOI: 10.12955/cbup.v7.1471

Keywords: persimmon, tanning substances, pectin

\section{Introduction}

The economic progress of countries is not possible without the development of efficient and wastefree technologies and the search for a new raw material potential as natural resources run low with each passing year and cannot be restored. Therefore one of the principal directions for industrial development is to find and to utilize inexpensive unconventional raw materials or industrial waste as a new raw-material base. On the other hand, factories dump a great amount of waste thus aggravating the ecological situation in developed countries and, what is more important, have a detrimental effect on human health (Jung et al., 2005; Kim et al., 2006; Jinyu Chen et al., 2016; Khademi et al., 2013). The development of genetic engineering gradually excludes natural food products from human nutrition creating a so-called endoecological problem (Akagi et al., 2010; Vinha et al., 2012; Jung et al., 2009; Chung et al., 2015; Park et al., 2011). One of the new good-potential raw materials is persimmon. Subtropical persimmon is among the most popular crops. It is cultivated in every Georgian region due to its easy adaptability to many different soil-climatic conditions and good disease-resistance (Tal Kanety et al., 2014; Park et al., 2006). Among subtropical crops, persimmon comes second for its abundance and yield capacity and it is listed among the top crops for its nutritious value, i.e. the content of sugars, polyphenols, pectin and other substances (Ramin et al., 2003; Takahashi et al., 2006; Özdemir et al., 2009). Its high yield capacity makes this crop very profitable: its fruit grow and get ripe till the end of vegetation so the harvest time comes late in the season. Persimmon fruit do not have a long shelf life and are mostly consumed fresh (Zhide Zhou et al., 2018;

\footnotetext{
${ }^{1}$ Batumi Shota Rustaveli State University, Faculty of Natural Sciences and Health Care, Department of Chemistry, Batumi, Georgia, irina_bejanidze@live.ru

${ }^{2}$ Batumi Shota Rustaveli State University, Faculty of Natural Sciences and Health Care, Department of Chemistry, Batumi, Georgia, tina.kharebava @ mail.ru

${ }^{3}$ Batumi Shota Rustaveli State University, Faculty of Technologies, Department of Agrotechnology \& Engineering, Batumi, Georgia, nargizalasania@mail.ru

${ }^{4}$ Batumi Shota Rustaveli State University, Faculty of Natural Sciences and Health Care, Department of Chemistry, Batumi, Georgia, natali.did@ mail.ru

${ }^{5}$ LTD Batumi Water, of chemical-bacteriological laboratory, Batumi, Georgia, nazidavitadze@mail.ru
} 
Yoko Matsumura et al., 2016). Georgia can supply up to 30 tons of persimmon, and there is a potential for expanding persimmon orchards, however, up to $50 \%$ of the harvested fruit are wasted as no industrial technologies for fruit storage and processing have been developed up to this date, and neither have any appropriate/systematic studies of persimmon qualitative and quantitative parameters been done (Torkun Mamet, et al., 2018; Kondo et al., 2004).

Objects of Study: The purpose of this project was to study the persimmon fruit chemical composition, the regularity in the quantity changes of the bioactive substances and technical-economical persimmon parameters during its storage and technological processing; to develop a highly profitable and efficient composite production technology for a new assortment of products and high quality beverages.

\section{Materials and methods}

Our research was performed for 12 persimmon (Diospyros Kaki L) varieties cultivated in the Georgian subtropics and having significant practical importance: Khachia, Tomopan, Sidles, Adreula, Kostata, Saburosa (very astringent fruit), Khiakume, Zendji-Maru,Trueu-Maru,Gosho-zaki (mildly astringent fruit) and XX Century, Chinebuli (non-astringent fruit) (Fig.1).

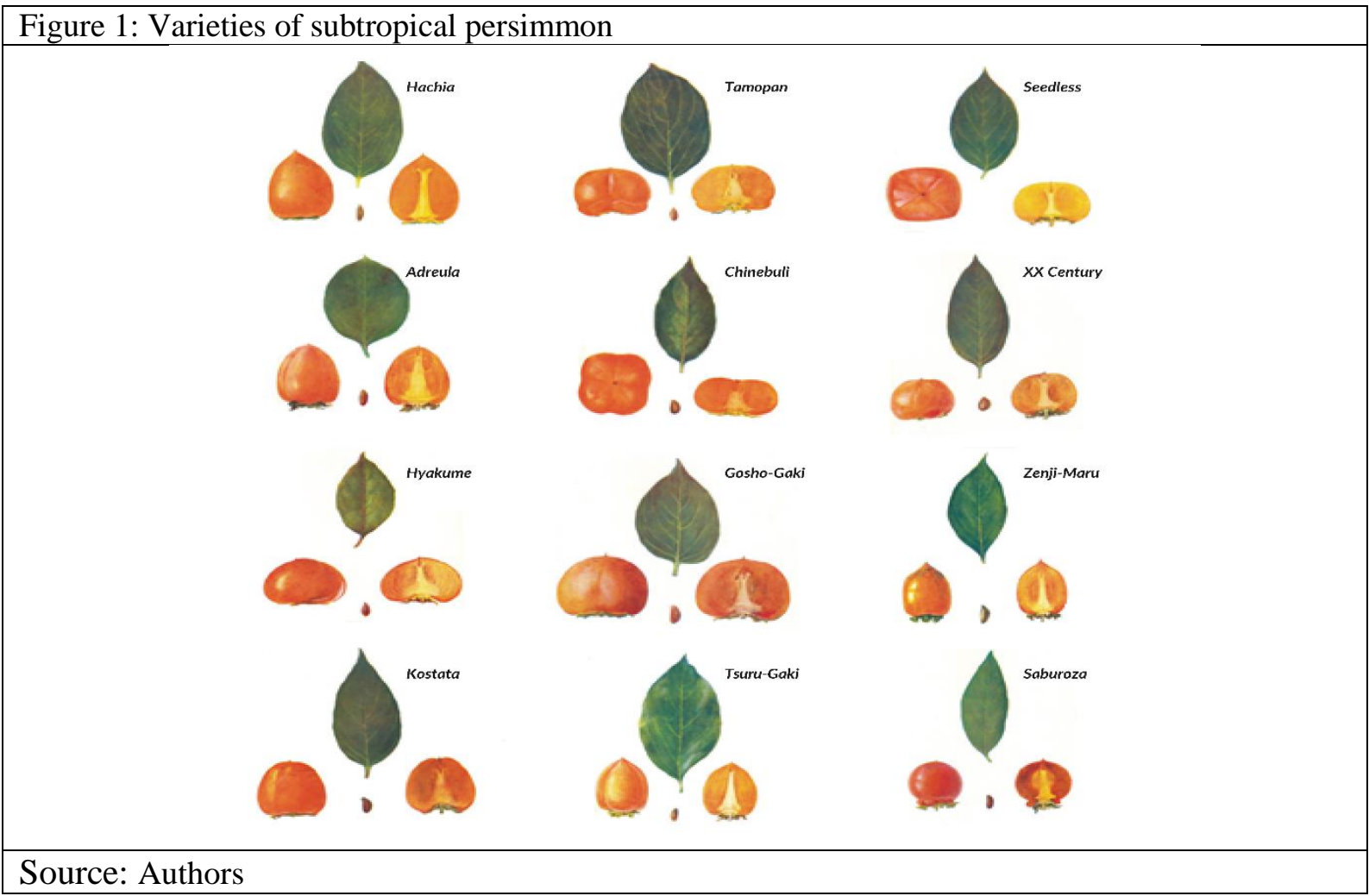

The fruit astringency was determined by organoleptic analysis, the fruit chemical composition was defined according to the approved standard methods. The study was performed on the fruit at the technical maturity stage. We determined the content of sugars (inverted, total, saccharose), tanning substances (free, total), polyphenols and nitrogen through a spectrophotometric

method, dry solids through a refractometric method, pectin (total, soluble, protopectin) and acidity through a potentiometric method, cellulose through a chlorite method and also the dynamics in the change of these components in the process of fruit storage and ripening (Standardinform, 2017). Besides that, we determined the qualitative polyphenol content, the relation of the nitrogen and cellulose content to the fruit maturity degree, as well as the tanning substance relation to the fruit astringency, one of the important organoleptic persimmon properties.

\section{Results and discussion}

In the first place, chemical and organoleptic analyses of persimmon fruit at their technical maturity condition were conducted for sugar content (total, inverted, saccharose), dry solids, pectin (total, soluble, protopectin), tanning substances (total content and free substances), acidity, and the dynamics in the change of these parameters during the fruit ripening and storage. Nitrogen and cellulose content 
was also determined along with their relation to the fruit maturity degree. The analyses were carried out according to state standard methods. It has been established that the content of the major components of extractive substances (\%) in different persimmon fruit varieties is as follows: 14.0 20.3 of dry solids; $13.0-19.1$ of total sugars $(0.4-1.8$ of saccharose and $12-18.2$ of inverted sugars); $0.05-0.18$ of acidity and $0-2.35$ of polyphenol substances. The data are presented in Figures 2 - 4.
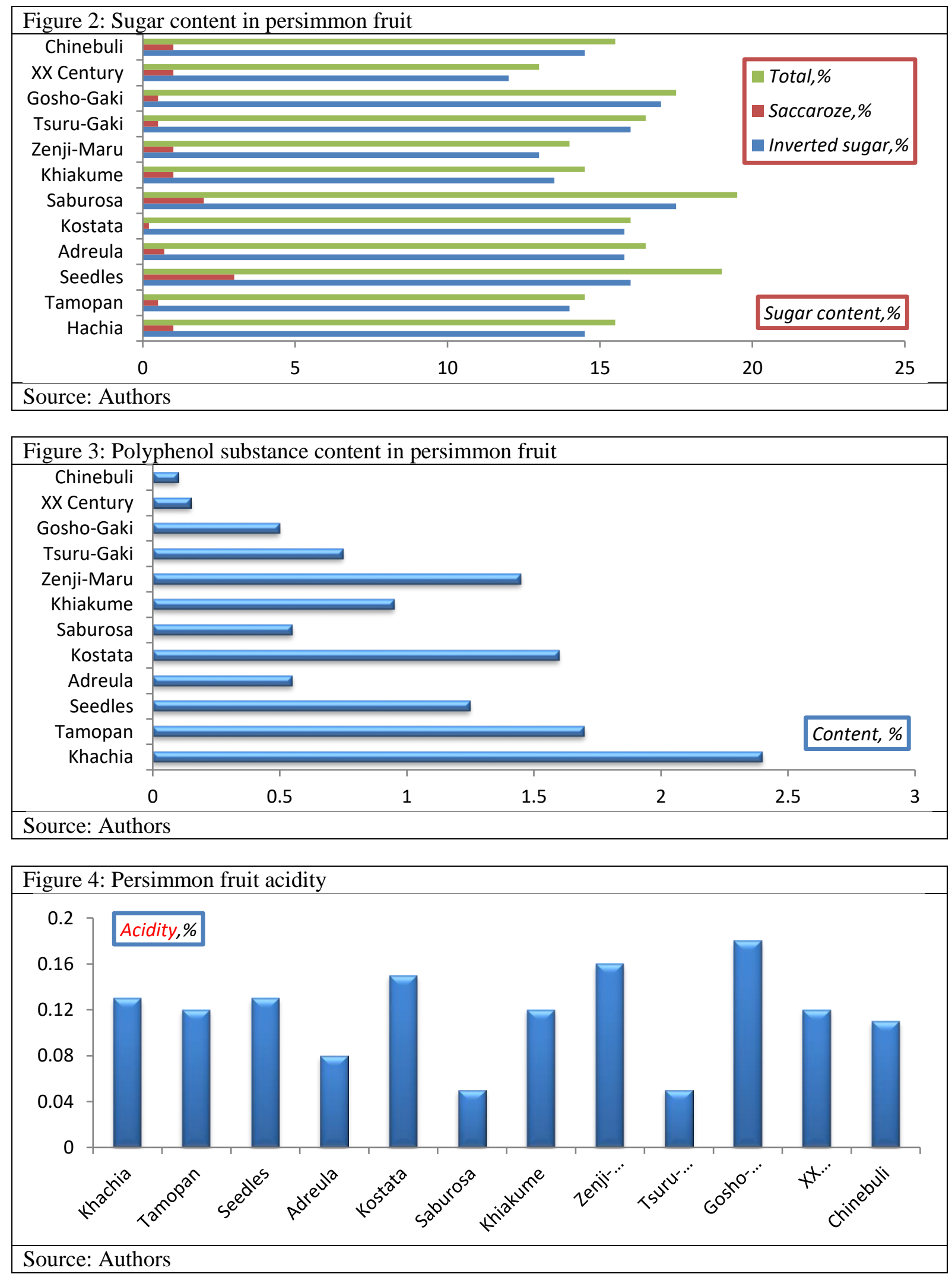
The above data show that inverted sugars (glucose and fructose) exceed other sugars in persimmon fruit, the acidity is rather low, and the polyphenol substance content depends on the fruit astringency, that is with the lower astringency the polyphenol substance quantity also gets lower, moreover in the fruit of XX Century and Chinebuli varieties having no tart taste it actually drops to zero.

It has been established that in astringent fruit the polyphenol substance content changes within 0.6 $2.35 \%$ and the mean value makes $1.48 \%$, in mildly astringent fruit it is $0.51-1.95 \%$ with the mean value being $1.23 \%$, and in non-astringent fruit it is $0-0.04 \%$ falling down to near zero $(0.02 \%)$.

During the persimmon fruit ripening on a tree their mass grows and extractive substances pile up; we studied the accumulation dynamics of extractive substances taking fruit of two varieties: tart Khachia fruit and mildly tart Khiakume fruit (Figures 5 -8).

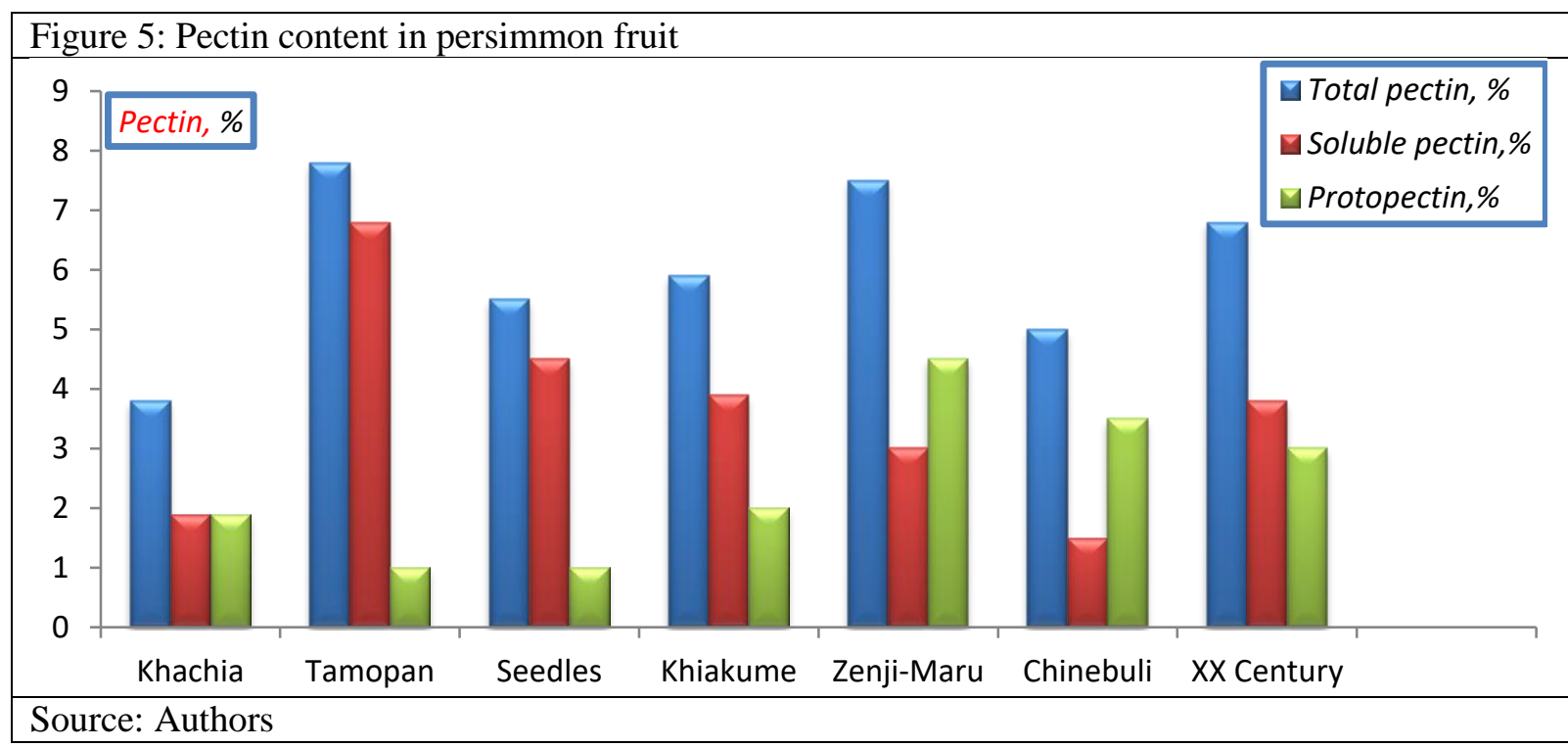

In other species, the pectin content is insignificant. According to the data obtained, in our opinion, Khachia and Khiakume varieties are suitable for technological processing, therefore, these persimmon varieties were further investigated.

The presented data show that sugar concentration in fruit increases along with their ripening, i.e. it grows 4.3 times in Khachia fruit and 2.3 times in Khiakume fruit, whereas the tanning substance content in the fruit of both varieties decreases to 4 times less than before ripening occurs. Polyphenol substances have a significant effect on the fruit taste formation. Their high content, on the one hand, enhances fruit vitamin activity and fruit resistance to phitopatogenic microorganisms, and, on the other hand, they have a negative effect on the taste properties of the products made from such fruit.

The polyphenol substance content in fruit is found to fall during the persimmon ripening on a tree as they transfer from a free state into a combined condition, that is they form compounds with proteins, high molecular compounds and with protein substances (Fig.8). However, by the end of ripening the polyphenol compound content remains rather high.

It has been of practical importance to establish the relationship between fruit astringency and their polyphenol substance content as it is astringency that determines persimmon fruit flavour properties, their harvest time and processing technology modes. Astringency has been established to depend not on the total content of polyphenols but on their concentration in a free state, and if it is lower than 70 $\%$, then the persimmon fruit have no tart flavor.

Pectin substances make one more important component of persimmon fruit, they take a major part in the physiological processes of fruit ripening and due to this they have a big effect on their quality. Therefore the persimmon fruit qualitative and quantitative composition was further determined. The research was done on persimmon fruit of seven varieties. The data presented in Fig.9 show that during the ripening process from July till November the pectin substance content decreases $40 \%$ in the Khachia variety and there is a slight $10 \%$ decrease in the Khiakume variety. During the fruit storage (25 days), they were tested for their content of soluble, insoluble (protopectin) and total pectin. It was 
established (Fig.10) that the pectin content decreases 50-55\% with the significant protopectin content decreasing in the first 10 days and then no protopectin content change afterwards.
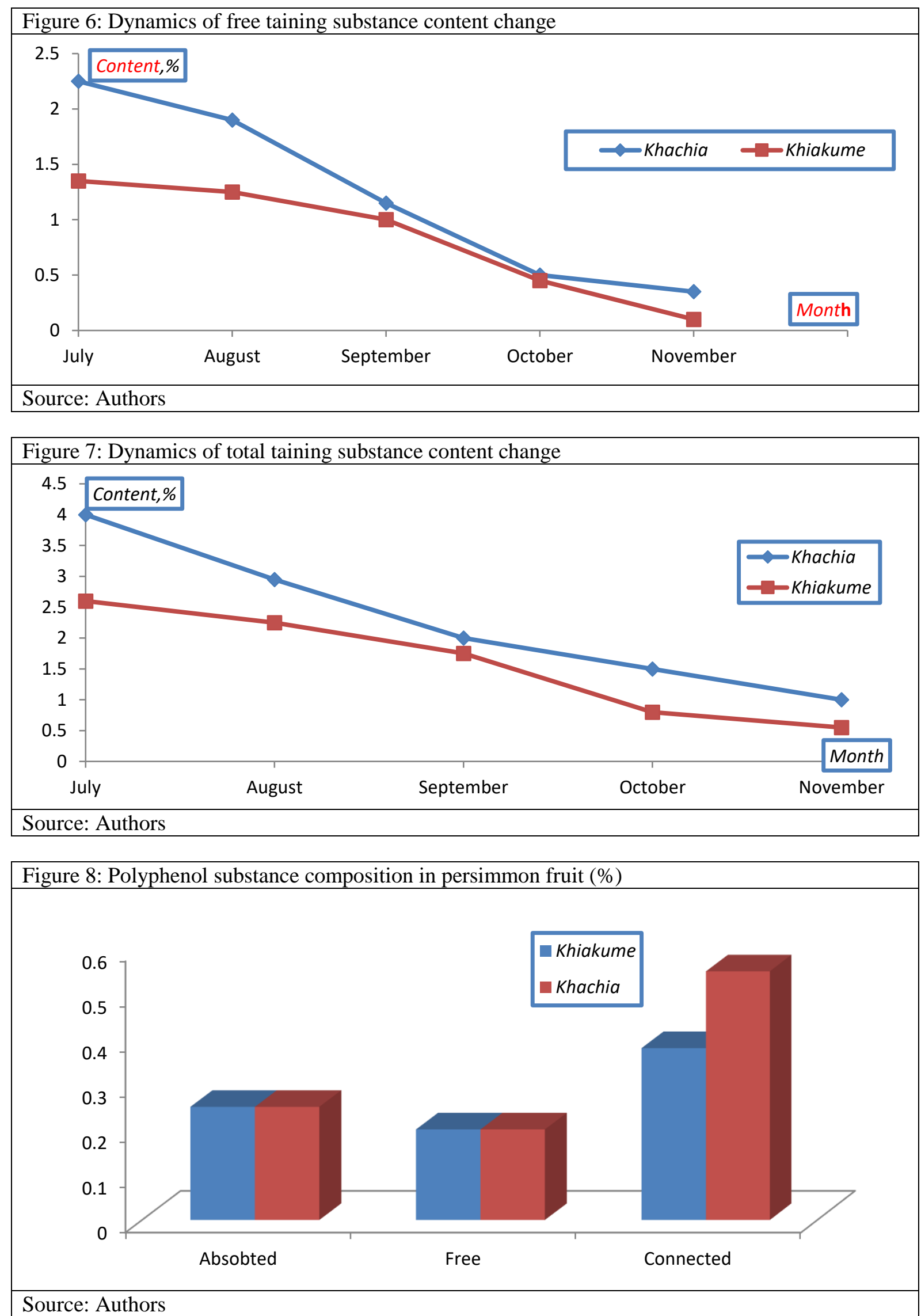


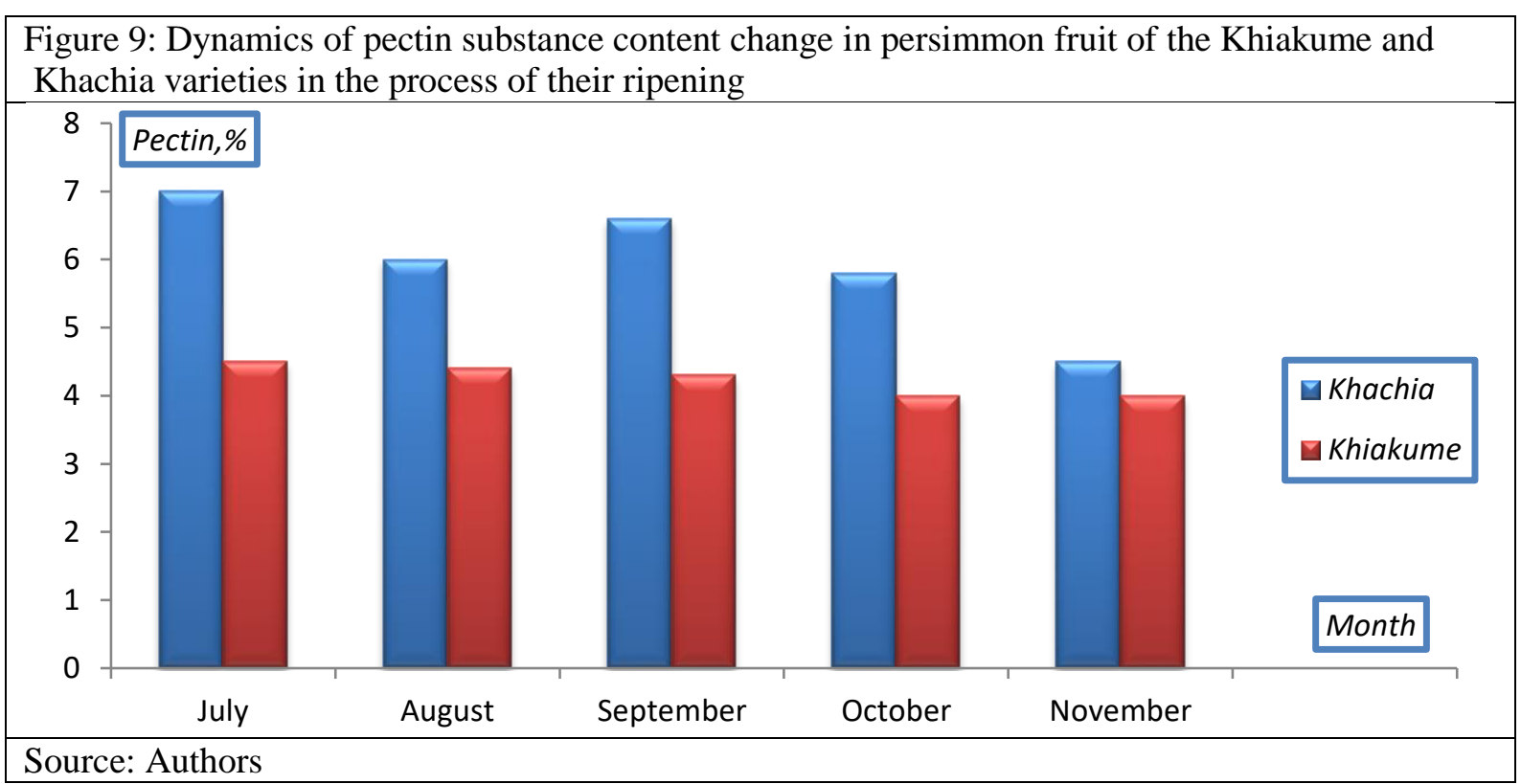

As it is shown by the given data, persimmon fruit have rather high content of soluble pectin which forms due to the protopectin hydrolysis during fruit ripening.

It has been established that when a fruit is at the technical maturity stage, the protopectin content is higher than the soluble pectin content; but if a fruit is at the biological and

physiological stage of ripeness, the picture is quite different with the soluble pectin content being higher.

Accumulating in blood nitrogen causes anaemia so the nitrogen content must be determined even if it is slight.

Cellulose also has an important part in human nutrition being a fibre that adsorbs toxic substances, heavy metals and bilious acids on its surface, and enhancing their removal from the organism.

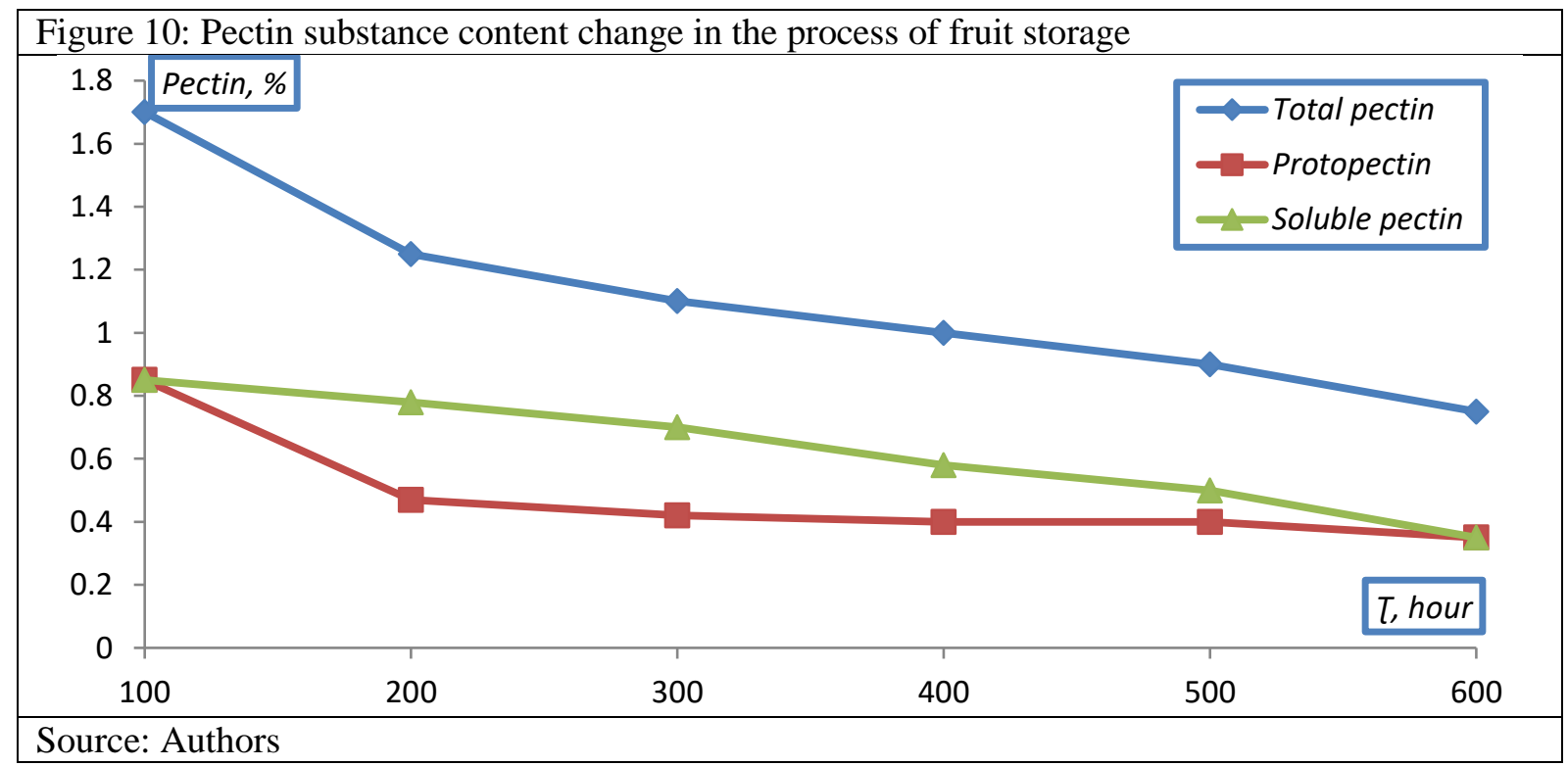

We determined the total nitrogen and cellulose content in the Khachia and Khiakume fruit varieties at different periods of their maturity and, in particular, within the period of their technical and physiological ripeness. The presented data (Fig.11) shows that the nitrous substance content only makes a slight change while the cellulose content gets $25 \%$ lower as cellulose transforms into carbohydrates in the process of fruit ripening 


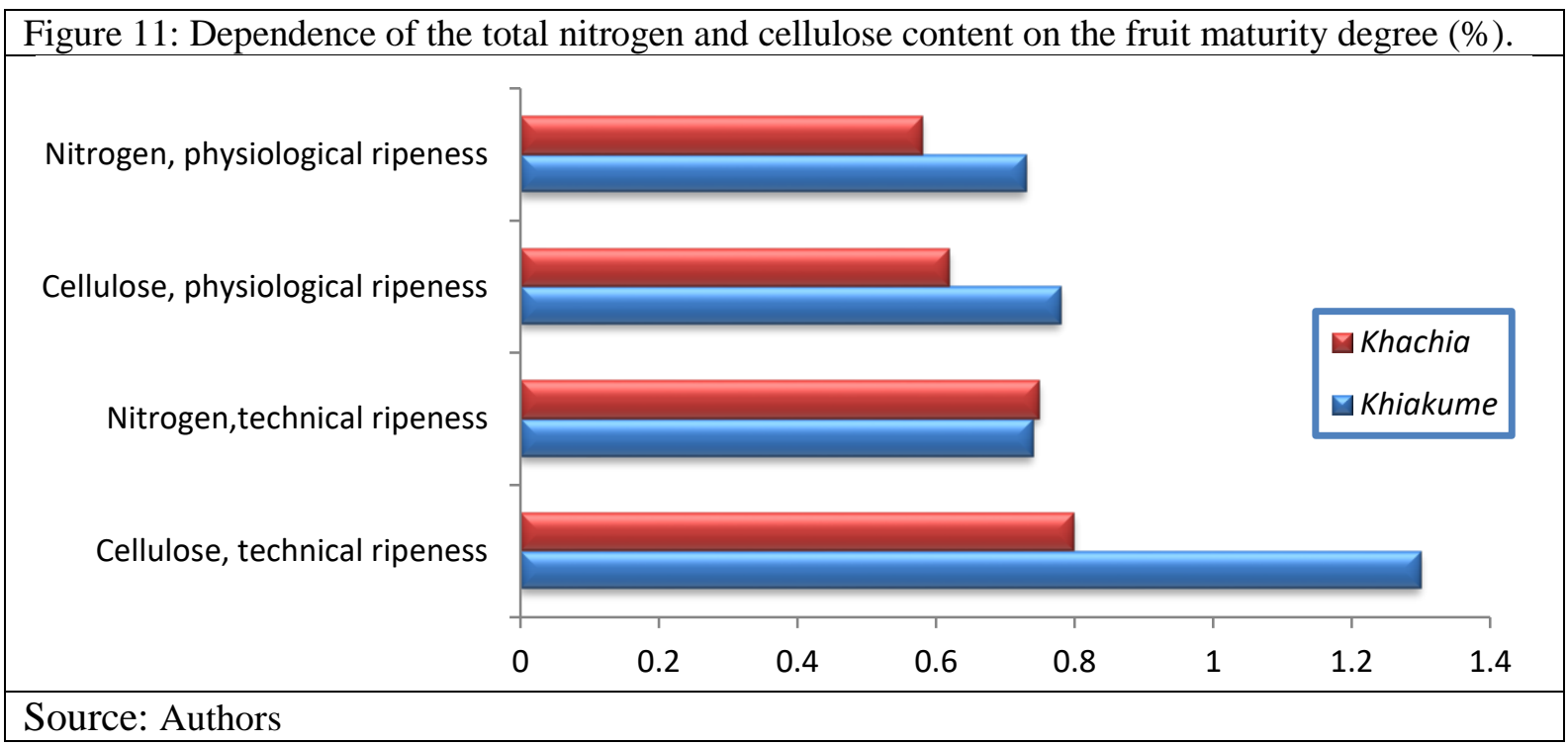

\section{Conclusion}

Organoleptic and chemical tests of 12 persimmon fruit varieties were made.

The content and composition of sugars, polyphenols, pectin, tanning substances, were defined as well as the relation of these parameters to the fruit maturity degree, the dynamics of their change in the ripening and storage process.

The feasibility of the persimmon fruit industrial processing was established. Persimmon fruit of the Khachia and Khiakume varieties were shown to be the best raw material for the industrial production of fruit alcohol and beverages. It should be noted here that persimmon fruit must be harvested in November when they have a dark orange colouring and their dry solids content reaches $18 \%$, inverted sugars make $16-16.5 \%$, and the acidity is $0.12 \%$.For concentrate production, persimmon must be harvested in October when the fruits are yellow and their tanning and colouring substances reach $1.24 \%$, and pectin substances make up $0.77 \%$. The fruit sugars are glucose and fructose in equal quantities. Tanning substances, leicoantocianes, in particular, are responsible for the tart taste; the lower their content is, the less the tart taste is felt, moreover, the ripe fruit are less tart in flavour which is due to the tanning substances getting bound with high molecular substances. All the 12 persimmon varieties cultivated in Georgia can be used as raw material, including substandard and overripe fruit that are not marketable and do not have a long shelf life.

\section{References}

Akagi. T., Suzuk, Y., Ikegami, A., Kamitakahara, H., Takano, T., Nakatsubo, F., Yonemori, K (2010). Condensed tannin composition analysis in persimmon (Diospyros kaki Thunb.) fruit by acid catalysis in the presence of excess J Jap Soc Hort Sci 79, 275-281.

Jung, S.T., Park, Y. S., Zachwieja, Z. (2005). Some essential phytochemicals and the antioxidant potential in fresh and dried persimmon. J Food Sci Nutr, 56, 105-113. https://doi: 10.1080/09637480500081571

Jinyu, Chen., Jing, Du., Zhen, Ge., Wie, Zhu., Rongzu, Nie., Chunmei, Li. (2016). Comparison of sensory and compositions of five selected persimmon cultivars (Diospyros kaki L.) and correlations between chemical components and processing characteristics. Journal of Food Science and Technology. 53(3), 1597-1607. https://doi: 10.1007/s13197-015-2102-y

Hun-Sik, Chung., Han-Soo, Kim., Young-Guen, Lee., Jong-Hwan, Seong. (2015). Effect of deastringency treatment of intact persimmon fruits on the quality of fresh-cut persimmons. Food Chemistry, 166, 192-197. https://doi: 10.1016/j.foodchem.2014.06.015

Kim, S.Y., Jeong, S.M., Kim, S.J. (2006). Effect of heat treatment on the antioxidative and antigenotoxic activity of extracts from persimmon (Diospyros kaki L.) peel. Biosci Biotechnol Biochem,70(4), 999-1002. https://doi:10.1271/bbb.70.999

Kondo, S., Yoshikawa, H., Katayama, R. (2004). Antioxidant activity in astringent and non-astringent persimmons. J Hortic Sci Biotechnol, 79, 390-394. https://doi:org/10.1080/14620316.2004.11511778

Khademi, O., Zamani, Z., Poor Ahmadi, E. and Kalantari, S. (2013). Effect of UV-C radiation on postharvest physiology of persimmon fruit (Diospyros kaki Thunb.). International Food Research Journal 20(1), 247-253.

Özdemir, A. E., Çandır, E. E., Toplu, C., Kaplankıran, M., Yıldız, E. and Inan, C. (2009). The effects of hot water treatments on chilling injury and cold storage of 'Fuyu' persimmons. African Journal of Agricultural Research 4, 1058-1063. 
Park, Y.S., Jung, S.T., Kang, S.G., Ayala, A. L. M., Tapia, M. S. (2006). Drying of persimmons (Diospyros kaki L.) and the following changes in the studies bioactive compounds and the total radical scavenging activities. LWT, 39, 748-755. https://doi:10.1016/j.lwt.2005.05.014

Ramin, A. A., Tabatabaie, F. (2003). Effect of Various Maturity Stages at Harvest on Storability of Persimmon Fruits (Diospyros kaki L.). J. Agric. Sci. Technol. 5, 113-123

Soo Jeong, Park. (2011). Dry weight and carbohydrate distribution in different tree parts as affected by various fruit-loads of young persimmon and their effect on new growth in the next season. Scientia Horticulturae, Volume 130(4), 732-736. https://doi:10.1016/j.scienta.2011.08.029

Tal, K., Amos, N., Am, G., Uri, Dn., Lemcoff., J.H., Shabtai, C. (2014). Irrigation influences on growth, yield, and water use of persimmon trees. Irrigation Science. 32(1), 1-13.

Takahashi, M., Watanabe, H., Kikkawa, J. (2006). Carotenoids extraction from japonese persimmons (Hachiya kaki) peels by supercritical $\mathrm{CO}_{2}$ with ethanol. Anal. Sci, 22, 1441-1447. https://doi.org/10.2116/analsci.22.1441

Torkun, M., Zhen-zhen, G., Ying, Z., Chun-mei, L (2018).Interactions between highly galloylated persimmon tannins and pectins. International Journal of Biological Macromolecules, 106,410-417 https://doi.org/10.1016/j.ijbiomac.2017.08.039

Yoko, M., Toshihiro, I., Hisakazu, Y., Eiji, K., Keiichi, M., Masatoshi, O., Azusa, F., Yuka, M., Mitsuru, S., Yasue, N., Shinichi, K. (2016). Data in support of antioxidant activities of the non-extractable fraction of dried persimmon (Diospyros kaki Thunb.). Data in Brief, 8, 1247-1254 https://doi.org/10.1016/j.dib.2016.07.004

Zhide, Zhou., Yon, Huang., Jintao, Liang., Minglin, Ou., Jiejing,Chen., Guiyin, Li (2016).Extraction, purification and antiradiation activity of persimmon tannin from Diospyros kaki L.f. Journal of Environmental Radioactivity, 162-163, 182-188. https://doi.org/10.1016/j.jenvrad.2016.05.034

Standardinform (2017). Fruit processing products and vegetables. Moscow. 